\title{
Managerial quality and worker productivity in developing countries
}

\section{Business consulting and supervisory skills training can improve firm productivity and labor relations}

Keywords: managerial quality, worker productivity, labor relations

\section{ELEVATOR PITCH}

Productivity differences across firms and countries are surprisingly large and persistent. Recent research reveals that the country-level distributions of productivity and quality of management are strikingly similar, suggesting that management practices may play a key role in the determination of worker and firm productivity. Understanding the causal impacts of these practices on productivity and the effectiveness of various management interventions is thus of primary policy interest.

\section{KEY FINDINGS}
Pros
๑ Adoption of management practices may improve quality and efficiency as well as encourage organization learning, thus leading to higher productivity.
$\oplus$ Adoption of management practices enables firms to delegate more and achieve higher long-term expansion rates.
๑ Managers who are more highly skilled are better able to deal with shocks to worker productivity and allocate human resources more efficiently.
๑ Supervisory skills training may improve supervisor-worker relations and raise the well- being of workers.
- Specific training programs may help correct the misallocation of managerial talent and reduce the gender gap in managerial leadership.

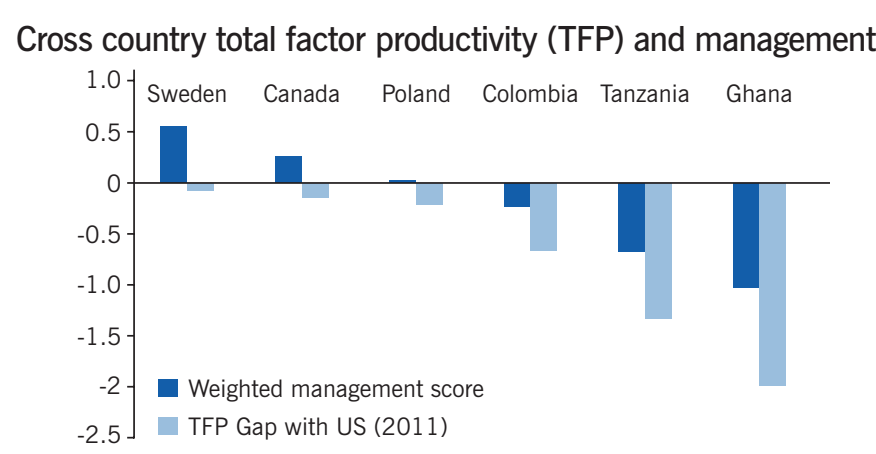

Source: [1].

\section{Cons}

- Most business training programs for micro and small firms have only modest effects on managerial quality and firm performance.

- The take-up of training programs can be very low due to information barriers, distrust, time constraints, and attrition concerns.

- Changing practices may result in adjustments in team dynamics and lower productivity in the short term.

- Managers may not be able to implement the required changes due to misalignment of firm incentives and worker resistance.

\section{AUTHOR'S MAIN MESSAGE}

Emerging evidence demonstrates that improving managerial quality can generate considerable increases in productivity. Some supervisory skills training programs have improved labor relations and narrowed the gender gap in managerial leadership. However, changing practices may face resistance from workers and result in adverse short-term effects on productivity. Potential benefits may outweigh temporary costs, and policymakers should therefore promote managerial training programs by providing both financial and organizational support. 


\section{MOTIVATION}

Economists have long noticed the large and persistent differences in labor productivity across firms and countries. Growth accounting literature reveals that physical and human capital can only partially explain the variation. Another important driver of productivity differences, as proposed by business economists, is managerial quality, referring to either the talents of the managers themselves or the quality of their practices. To measure managerial quality, some researchers focus on the latter. For example, one study developed an innovative survey instrument to collect data on management practices from 732 medium-sized firms in four high-income countries [2]. The results suggest a strong association between management practice scores and firm-level performance measures such as profitability and productivity. In a similar fashion, a recent study developed a series of questions to measure the business practices of microenterprises in seven developing countries [3]. It finds that variation in business practices explains as much of the difference in firm outcomes in microenterprises as in larger firms.

Instead of focusing on management or business practices, some researchers construct a measure of managerial quality based on the characteristics (i.e. talents) of managers and supervisors. For instance, a study from 2016 finds evidence in Indian garment factories that production lines supervised by managers who have higher monitoring and problemsolving ability exhibit higher productivity [4].

However, the above results raise several important questions and puzzles. First, although recent studies have found that managerial quality is strongly correlated with firm performance, it is unclear whether the correlation lines up with causation. If it does, what are the mechanisms through which managerial quality affects productivity? Second, most studies focus on innate managerial ability and it remains unclear whether management skills can be acquired through learning. In other words, researchers still need to know whether business consulting and training programs are effective at improving managerial quality and, consequently, firm performance. Finally, if participating in business consulting and training programs is profitable, why are firms not more apt to take advantage of them? What are the barriers to the adoption of management practices and the take-up of training?

\section{DISCUSSION OF PROS AND CONS}

\section{Does causation exist? Evidence from experimental studies}

Although existing studies have found that managerial quality is strongly correlated with firm performance, it is less clear whether a causal link exists. Chances are that it is more profitable or easier for better-performing firms to adopt standard management practices. Alternatively, it may be that omitted determinants of productivity, such as institutional organization, have also contributed to differences among managerial practices.

To explore the potential causality, most research exploits management interventions that provide consulting or training services to randomly chosen firms, and compares their performance to a set of control firms. Since the two sets of firms are essentially similar prior to the intervention, any subsequent differences should reflect the causal impact of improved managerial quality. Disappointingly, most evidence from randomized experiments among microenterprises suggests only modest effects, if any, of business 
training on productivity. For example, one such study finds that the most commonly used business training course offered among female entrepreneurs in Sri Lanka has little impact on business profits, sales, or capital stock [5]. The recent study mentioned above, which assesses evidence from several training programs in microenterprises in seven developing countries, concludes that most of the training programs have insignificant impacts on outcomes due to a lack of impacts on improvement of business practices [3]. The authors argue that more intensive training programs may be needed.

A 2013 study reports the results of a management field experiment on large Indian textile firms, which provided professional and intensive consulting services on management practices to a set of randomly chosen treatment plants [6]. It finds that such consulting services lead to improvements in basic management practices, such as inventory management and cleaning of workspaces. Moreover, these improvements induce a $17 \%$ increase in productivity within the first year and lead to increases in firm size in the three years following the intervention. These results indicate that basic management practices can be imparted under certain circumstances, and that a causal link does exist between managerial quality and firm productivity. The generalizability of these results likely relies on the existing organizational structure and the size of the firms receiving management consulting, as well as the quality of the services provided. Additionally, the cost-benefit analysis reveals that the program is cost-effective. Specifically, the authors impute a total increase in annual profits of around $\$ 325,000$ per plant, exceeding the actual costs of $\$ 250,000$.

Another study evaluated the effects of a supervisory skills training program for garment factory supervisors in Cambodia, which aims to improve supervisor-worker relations by teaching supervisors effective leadership and communication skills [7]. In this research, supervisors were randomly chosen to enroll in a four-day, six-hour-a-day training course. Survey responses and factory administrative data were used to examine whether trained supervisors had better relationships with workers and whether workers' productivity was higher if supervisors were trained. Two facts stand out in the results. First, the training program has an overall positive impact on both the perception of job satisfaction and employee productivity. Second, training managers at different levels can have very different effects. In particular, training direct (lower-level) supervisors is more important for improving the "soft" dimensions of the work environment, such as job satisfaction and day-to-day guidance, while training indirect (higher-level) supervisors matters most for "hard" dimensions, such as improved productivity. Evidence from this study suggests that managerial skills are indeed teachable and do matter for both productivity and labor relations.

A related study provides additional evidence that managerial skills are teachable and can be acquired through learning [8]. In particular, it focuses on other general "soft" skills, such as communication, time management, and problem solving. Although these skills are not directly relevant for production, they do have a statistically significant and economically meaningful impact on worker productivity. The results show that female workers who have been randomly chosen to participate in the training program exhibit improved soft skills in key dimensions and substantially higher productivity up to nine months after program completion. The program is proven to be cost-effective, and it increases the likelihood of retention and promotion among treated workers. 


\section{Managerial quality and productivity: Potential mechanisms}

Emerging evidence demonstrates that, at least in large industrial firms in developing countries, intensive business training and consulting can improve managerial quality and generate considerable increases in productivity. This causal link raises further questions about the specific mechanisms at play and the role of management. In particular, how should researchers and policymakers think about management? What are the potential mechanisms through which improved managerial quality enhances firm productivity and profitability?

Some researchers view management as a factor of production, for example, as an intangible capital stock [9]. Meanwhile, since many studies have found spillover effects of management both within and across firms, some other researchers argue it may be more appropriate to think of management as a technology that raises total factor productivity [1]. Based on original survey data on over 11,000 firms in 34 countries, a group of researchers in the latter category find empirical results that are in line with the predictions of a "Management as a Technology" model [1], (as seen in Figure 1).

However, management may also matter in ways other than productivity. For example, management may also affect the demand faced by firms, prices of raw materials, cost of finance, and the willingness of banks to lend [3].

Experimental evidence from Indian textile plants suggests that, in the short term (within the first year), improved managerial practices lead to higher productivity through improved quality and efficiency and reduced inventory [6]. For example, measuring,

Figure 1. Cross country total factor productivity (TFP) and management

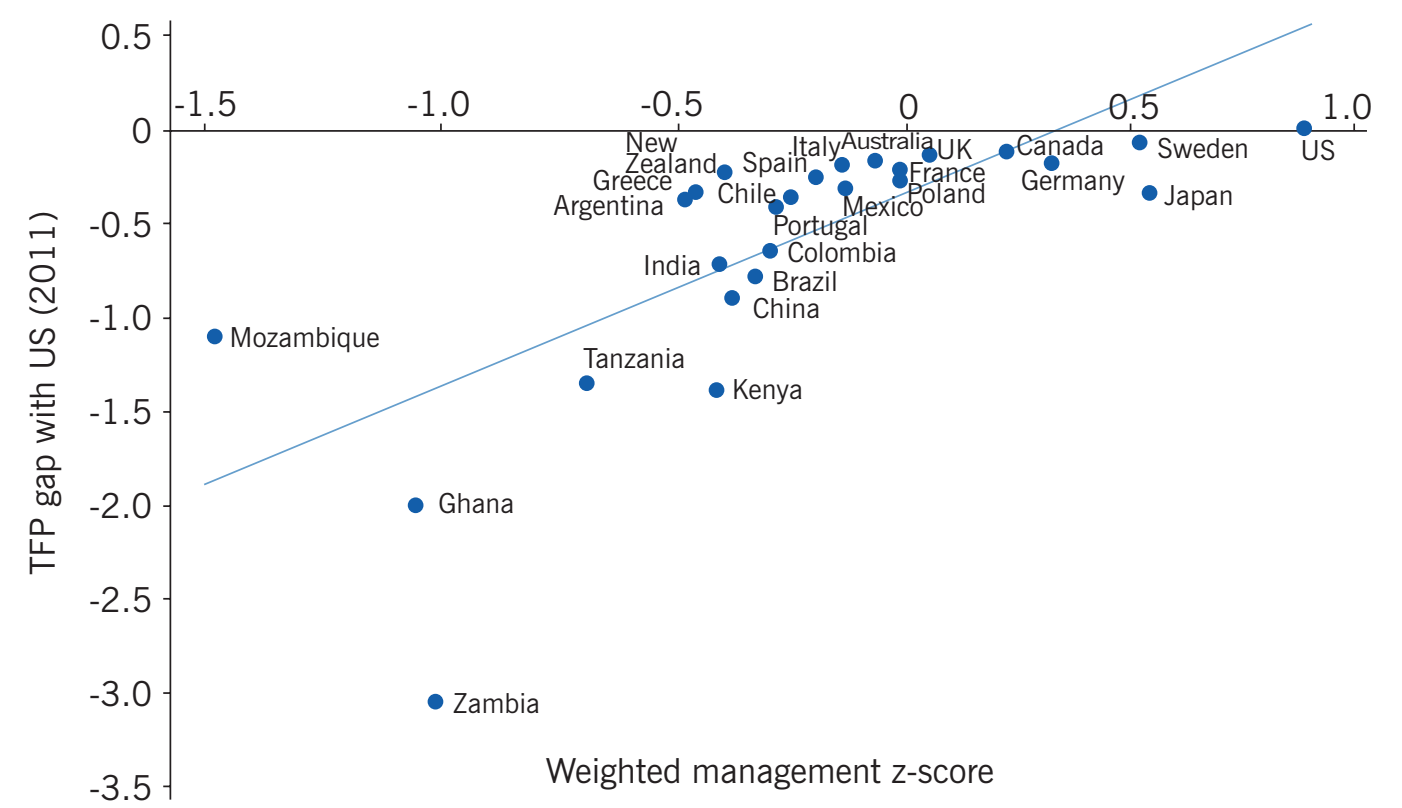

Note: The $x$-axis is a standardized management score that summarizes the quality of firms' managerial practices averaged within country. The $y$-axis is the gap in total factor productivity (TFP) between each country and the US, where TFP is calculated from the residual of a production function estimation.

Source: Bloom, N., R. Sadun, and J. van Reenen. Management as a Technology? Harvard Business School Strategy Unit Working Paper No. 16-133, 2016 [1]. 
classifying, and tracking defects allows firms to rapidly address quality problems, resulting in huge reductions in defects. Better records and storage practices lead to a significant fall in inventory and dead stock. In the longer term (three years following the start of the intervention), firm size increased for the treated firms because the adoption of management practices allowed owners to oversee more production activities and delegate more decisions to their plant managers. These findings underscore two main takeaways. First, it is important for impact evaluation studies of management practices to look beyond the short and medium term to analyze long-term business outcomes, including longevity and business growth. Second, better management may only help on a larger scale, implying that policy interventions that target larger firms may be more desirable.

A recent study identifies another channel through which management matters [4]. Specifically, it finds that productivity suffers in response to higher indoor air pollution exposure (due to reductions in the short-term physiological and cognitive functioning of workers), but that supervisors of higher managerial ability are able to mitigate such productivity loss through frequent task reallocation and replacement of underperforming workers. Using hourly data on production, the study finds that lines supervised by managers with higher managerial quality scores exhibit higher productivity. This demonstrates that supervisors of higher management ability matter, in that they are better able to deal with shocks (i.e. short-term spikes in the cost of effort) to worker productivity.

A 2015 study on Bangladesh documents how a management practice that encourages information sharing and knowledge exchange within a firm could increase productivity [10]. Since different lines in Bangladeshi garment factories may start producing the same style of product on different days, when a given line starts producing a new product, there may be others that have already acquired relevant production experience. The study's author ran a randomized experiment in which random pairs of workers were instructed by their supervisors to share production knowledge and experience when one worker started producing a garment that the other had already produced. The results suggest that the intervention has a nontrivially positive impact on the initial productivity of the later-starting workers. Therefore, managerial quality may affect productivity by providing a better environment for organizational learning.

\section{Barriers to the adoption of management practices and the take-up of training?}

A common research question in this field is "why are firms not taking more advantage of business training and consulting programs if they are profitable?" Speculative evidence points to information barriers as the primary factor [6]. In particular, it appears that many firms do not believe that simple and widespread practices can improve profits. Additionally, there is a lack of awareness of less common practices among firm owners.

Misalignment of incentives within firms could be another barrier to the adoption of seemingly profitable management practices or training programs [11]. A study conducted in Pakistan examined the introduction of a new cutting technology that reduces total costs of soccer ball production by $1 \%$. The authors randomly allocated the new technology to a subset of soccer ball producers, but found a surprisingly low take-up rate. Additional evidence suggests that the lack of adoption was mainly due to the resistance of influential 
employees who feared that the new technology could lead to reductions in their effective wage, and thus strategically misinformed owners about the value of the technology. After a one-time incentive payment to these key employees, take-up of the new technology rose immediately.

In other cases, even if managers have full information and are willing to make changes to their management practices, it can be difficult for them to do so. One reason for this is challenges due to informal norms. A study from Bangladesh noticed that women are extremely underrepresented in supervisor positions in the Bangladeshi garment sector [12]. Although female workers account for $80 \%$ of the workforce, $95 \%$ of supervisors are male. Most workers, including female workers, believe men are more effective supervisors than women. However, a test on skill and professional knowledge revealed that the perception does not match reality: female workers who were chosen to be promoted as supervisors tended to be as qualified as male workers. To correct the misallocation of managerial talent, the authors conducted an experiment that provided training services to both male and female workers selected by the factory. As a result, the probability of being promoted or tried out as a supervisor increased among female trainees. However, the promotion of women led to changes in team dynamics. In particular, the resistance of line workers (including female workers) to their new female supervisors caused decreases in the lines' initial productivity. Moreover, promotion of female workers demotivated male workers and increased their attrition rates, as they became more pessimistic about later promotion.

Another related study used a marketing experiment to explore the demand for training services in the Bangladeshi garment sector [13]. The authors reached out to selected garment factories through phone calls to assess their interest in a training program for line supervisors. The overall take-up turned out to be extremely low. Consistent with prior studies, the authors find one of the primary reasons for non-adoption is that decision makers do not believe in the training's effectiveness. Additionally, pulling supervisors off the line to train them leads to short-term decreases in productivity, especially in the garment sector where production pressure is high and managers are severely time constrained. Moreover, firms are unwilling to invest because they are afraid trained supervisors will leave the factory after completing the training.

\section{LIMITATIONS AND GAPS}

While intensive and expensive business training and consulting have been proven to be effective at improving profitability and productivity among large industrial firms, evidence from training programs in microenterprises is quite mixed. It is unclear whether firm size or training intensity drives these results.

A further limitation involves the time frame under consideration in the majority of the studies. Most of the research focuses on short-term effects, and there is a relative dearth of evidence on the long-term impacts of management intervention.

Finally, little is known about the cost-effectiveness of various training programs. On the one hand, it is difficult to evaluate the benefits in the longer term; on the other hand, some benefits such as gender equality and perceived satisfaction of workers are intrinsically hard to measure. 


\section{SUMMARY AND POLICY ADVICE}

Adopting widespread scientific management practices and improving the managerial skills of supervisors can significantly improve worker productivity and firm profitability. Although some programs have generated incredibly high rates of return, many firm owners in developing countries do not believe in the effectiveness of business training or consulting programs. Results from a marketing experiment in the Bangladeshi garment sector show that the demand for training services is extremely low and very elastic to prices.

Government intervention may be leveraged to change firm managers' beliefs. In particular, subsidies could be provided to encourage the adoption of certain management practices and the take-up of training programs. Publicly funded training could serve to demonstrate the cost-effectiveness of proven training programs. In addition, the fixed cost of developing an effective training program can be very high, which may deter individual firms from engaging in program design and development. Government could capture the potential market gains from high-quality training by investing in and creating effective programs and making them easily accessible to firms. To reduce information barriers and increase the awareness of training services, governments might promote information sharing among firms by organizing conferences and workshops. Finally, antitrust policies and trade liberalization policies may be helpful, since increased competition will drive badly managed firms out of the market and force firms to improve managerial quality.

\section{Acknowledgments}

The author thanks an anonymous referee and the IZA World of Labor editors for many helpful suggestions on earlier drafts. The author thanks Huayu Xu and Lavanya Garg for excellent research and editorial support, and Anant Nyshadham and other co-authors for countless valuable discussions regarding this research agenda.

\section{Competing interests}

The IZA World of Labor project is committed to the IZA Guiding Principles of Research Integrity. The author declares to have observed these principles.

(c) Achyuta Adhvaryu 


\section{REFERENCES}

\section{Further reading}

McKenzie, D., and C. Woodruff. "What are we learning from business training and entrepreneurship evaluations around the developing world?" The World Bank Research Observer 29:1 (2014): 48-82.

Bloom N., R. Lemos, R. Sadun, D. Scur, and J. Van Reenen. "JEEA-FBBVA Lecture 2013: The new empirical economics of management." Journal of the European Economic Association 12:4 (2014): 835-876.

\section{Key references}

[1] Bloom, N., R. Sadun, and J. Van Reenen. Management as a Technology? Harvard Business School Strategy Unit Working Paper No. 16-133, October 2016.

[2] Bloom, N., and J. Van Reenen. "Measuring and explaining management practices across firms and countries." The Quarterly Journal of Economics 122:4 (2007): 1351-1408.

[3] McKenzie, D., and C. Woodruff. "Business practices in small firms in developing countries." Management Science 63:9 (2016): 2967-2981.

[4] Adhvaryu, A., N. Kala, and A. Nyshadham. Management and Shocks to Worker Productivity. Working Paper, October 2016.

[5] de Mel, S., D. McKenzie, and C. Woodruff. "Business training and female enterprise start-up, growth, and dynamics: Experimental evidence from Sri Lanka." Journal of Development Economics 106:C (2014): 199-210.

[6] Bloom, N., B. Eifert, A. Mahajan, D. McKenzie, and J. Roberts. "Does management matter? Evidence from India." Quarterly Journal of Economics 128:1 (2013): 1-51.

[7] Schoar, A. The Importance of Being Nice: Supervisory Skill Training in the Cambodian Garment Industry. Working Paper, 2013.

[8] Adhvaryu, A., N. Kala, and A. Nyshadham. The Skills to Pay the Bills: Returns to On-the-job Soft Skills Training. PEDL Research Papers, November 2016.

[9] Bruhn, M., D. Karlan, and A. Schoar. "What capital is missing in developing countries?" American Economic Review 100:2 (2010): 629-633.

[10] Menzel, A. Organizational Learning: Experimental Evidence from Bangladeshi Garment Factories. PEDL Research Papers, March 2016.

[11] Atkin, D., A. Chaudhry, S. Chaudry, A. K. Khandelwal, and E. Verhoogen. "Organizational barriers to technology adoption: Evidence from soccer-ball producers in Pakistan." The Quarterly Journal of Economics 132:3 (2017): 1101-1164.

[12] Macchiavello, R., A. Menzel, A. Rabbani, and C. Woodruff. Challenges of Change: An Experiment Training Women to Manage in the Bangladeshi Garment Sector. CAGE Working Paper No. 256, December 2015.

[13] Macchiavello, R., A. Menzel, A. Rabbani, and C. Woodruff. "The market for training services: A demand experiment with Bangladeshi garment factories." American Economic Review 105:5 (2015): 300-304.

\section{Online extras}

The full reference list for this article is available from:

https://wol.iza.org/articles/managerial-quality-and-worker-productivity-in-developing-countries

View the evidence map for this article:

https://wol.iza.org/articles/managerial-quality-and-worker-productivity-in-developing-countries/map 